\title{
Análisis comparativo de los perfiles demográficos y socioeconómicos de los migrantes internos e internacionales en México entre 1990 y 2015
}

Mauricio Rodríguez Abreu*

Recepción: 11 de septiembre de 2017 Aceptación: 11 de noviembre de 2017

Resumen El estudio de la migración en México por lo general ha explorado las características de los migrantes internos o internacionales en comparación con las de la población no migrante. En el presente artículo, usando información de fuentes mexicanas y estadounidenses, se comparan los perfiles de los migrantes internos, de retorno y emigrantes a Estados Unidos en el periodo 1990-2015. Usando análisis de correspondencias múltiples, se identifican las categorías de las dimensiones demográficas y socioeconómicas asociadas a cada tipo de migración, así como los cambios mostrados durante el periodo analizado. Los resultados señalan que algunas dimensiones que permitían diferenciar un tipo de migrante de otro se han mantenido y otras han cambiado, dando paso a perfiles más diversificados en las distintas modalidades migratorias.

PALABRAS CLAVE: selectividad, perfiles migratorios, retorno, emigración, migración interna.

\section{Comparative analysis of the demographic and socioeconomic profiles of domestic and international migrants in Mexico between 1990 and 2015}

Abstract Traditionally the study of migration in Mexico has focused on the characteristics of domestic or international migrants in comparison with those of non-migrants. The present analysis utilizes both Mexican and American data to compare the characteristics of domestic migrants with those of return migrants and recent migrants to the U.S.A. for the 1990-2015 period. By using Multiple Correspondence Analysis, it was possible to

Investigador asociado en El Colegio de México, mrabreu@colmex.mx 
identify the demographic and socioeconomic dimensions associated with each migratory category, and the changes these associations have displayed during the years analyzed. Findings from the analysis indicate the persistence of some differences across groups and time, but also some significant changes, resulting in more diverse migration profiles.

Introducción

éxico ha experimentado diversas migraciones a lo largo de su historia.
Por un lado, desde la segunda mitad del siglo Xx, el rápido proceso de
urbanización impulsado por el modelo de desarrollo de industrialización por sustitución de importaciones (ISI) contribuyó a que la población se dirigiera a los grandes centros urbanos que concentraban las oportunidades de empleo en el país (Partida, 2010; Sobrino, 2010). Posteriormente, la transición al modelo neoliberal enfocado en los mercados extranjeros, la flexibilidad laboral y la pérdida de protecciones sociales a los trabajadores, propició el crecimiento de la emigración de mexicanos a Estados Unidos, así como el desgaste de la dinámica migratoria internacional de carácter temporal y circular que había existido desde el siglo XIX. En años más recientes, el creciente control fronterizo, que incrementa los costos asociados a la migración, aunado a la recesión económica en Estados Unidos y los cambios demográficos en México, parecen haber desacelerado la emigración y propiciado el retorno (Zenteno, 2012). Asimismo, cambios en la dinámica migratoria interna restaron importancia a algunas regiones de México, tales como la frontera norte y la Ciudad de México, como destinos privilegiados, con el resultado incluso de saldos negativos en entidades que históricamente habían representado polos de atracción (Romo \& Téllez, 2013).

Es también durante este periodo que una serie de cambios estructurales han tenido como resultado modificaciones en los perfiles de los migrantes. Primero, en 1986 fue promulgada la Ley de Reforma y Control de la Inmigración (IRCA, por sus siglas en inglés), que brindó la oportunidad de legalización a millones de mexicanos en Estados Unidos, pero también intensificó los controles fronterizos, lo cual ha sido identificado como el principal motor en el cambio de las características de los flujos migratorios entre México y Estados Unidos (Durand, 2016). Segundo, la firma del Tratado de Libre Comercio de América del Norte y la apertura comercial propiciaron la circulación de mercancías a la vez que restringían la migración, lo que tuvo como resultado una disrupción del patrón cíclico de la migración, mismo que se vio aún más deteriorado desde el reforzamiento de los controles fronterizos después de los atentados del 11 de septiembre de 2001 ( Durand, 2016; Fernandez-Kelly \& Massey, 2007; Tuirán \& Ávila. 2010). Tercero, la recesión económica de 2008-2009 
afectó considerablemente a la región, y en particular a sectores de la economía que representaban nichos para los trabajadores mexicanos (Villarreal, 2014).

El estudio de las características demográficas y socioeconómicas de los migrantes es un tema recurrente en la literatura. Sin embargo, un número reducido de trabajos ha contrastado las características de los migrantes inmersos en las distintas modalidades migratorias en México (véase Canales \& Montiel, 2007; Chávez, 1999). El estudio de las migraciones requiere integrar el estudio de las migraciones interna e internacional, pero hasta el momento el interés diferenciado en variables específicas que podrían explicar uno u otro tipo de desplazamiento y la inexistencia de fuentes de información que aborden ambas temáticas dificulta el análisis conjunto. El presente trabajo representa un esfuerzo por analizar de manera combinada las distintas modalidades migratorias. El objetivo principal es identificar las características sociodemográficas de los migrantes internos e internacionales recientes durante el periodo 1990-2015 y determinar si existen cambios en los perfiles migratorios que indiquen la desaparición de diferencias específicas entre los migrantes involucrados en las distintas modalidades.

\section{Antecedentes del estudio de las migraciones}

El estudio de las migraciones en México estuvo dominado en sus orígenes por el análisis de la dinámica interna. Inspirados por los trabajos de Zelinsky (1971) y Skeldon (1977), los principales análisis se enfocaron en el intenso proceso de urbanización que el país experimentaba y en ellos se vinculaban las migraciones al proceso de modernización y crecimiento urbano. Después de esta época, el desgaste del modelo ISI y la existencia de un sistema urbano consolidado, a la migración interna de carácter rural-urbano se sumaron distintos desplazamientos de tipo urbano-urbano, rural-rural e incluso urbano-rurales (Partida, 2010; Sobrino, 2010).

A partir de los años ochenta, como resultado de cambios en el modelo económico y en respuesta a las recurrentes crisis en el interior del país, dio un giro radical el patrón migratorio mexicano, de modo que desde entonces la migración MéxicoEstados Unidos se ha colocado en el centro de los estudios migratorios (Canales \& Montiel, 2007). Esta migración internacional, históricamente circular, masculina, rural y agropecuaria, movilizó millones de trabajadores de México a Estados Unidos como resultado de años de existencia de un sistema de enganche, programas de trabajadores temporales y un mercado de trabajo binacional consolidado (Tuirán \& Ávila, 2010). A su vez, esta migración dio paso a un periodo caracterizado por la inacción en materia de política migratoria, o la época que la política era no hacer política (Durand, 2016). Este periodo incorporó contingentes importantes de 
personas sin documentación migratoria y terminó en 1986 con la IRCA, mediante la amnistía otorgada a millones de personas y el endurecimiento de los controles migratorios (Durand, 2016; Nevins, 2010; Tuirán \& Ávila, 2010). Estas políticas tuvieron como resultado un nuevo ciclo migratorio de apertura comercial, pero también el cierre de fronteras a la migración, que dio cuenta de la participación de un más amplio y diverso conjunto de grupos sociales mexicanos (Leite, Angoa, \& Rodríguez, 2009), y en las últimas décadas una creciente heterogeneidad y complejidad de perfiles sociodemográficos y ocupacionales de los migrantes, tanto en sus características intrínsecas como en las relativas a las comunidades de origen y destino.

Aunado a lo anterior, en años recientes la migración mexicana a Estados Unidos ha presentado una reducción significativa en su dinámica. Iniciado a mitad de la primera década del siglo XXI, el descenso de la migración de mexicanos al país vecino representó alrededor del $60 \%$ de la migración anual máxima de casi un millón de migrantes en 2004 a poco más de 400 mil en 2010 (Pew Hispanic Center, 2011), hasta alcanzar un saldo migratorio casi nulo en los años más recientes (Zenteno, 2012).

Así como la literatura sobre migraciones en México ha tenido distintas áreas de interés, los enfoques teóricos que la han acompañado también han variado. El estudio de la migración interna ha enfatizado factores estructurales como las condiciones económicas y sociales de los lugares de origen y destino y factores individuales relacionados con las motivaciones (Sobrino, 2010). De esta manera, se han desarrollado modelos que intentan vincular los niveles de desarrollo de las distintas regiones de un territorio a las corrientes migratorias (Skeldon, 1977; Todaro, 1969, 1976; Zelinsky, 1971). Desde la economía neoclásica macroeconómica, la migración internacional y su contraparte interna responden a diferencias salariales entre regiones, con el resultado de trabajadores de las regiones con bajas retribuciones que se dirigen a lugares con altos salarios (Arango, 2003; Massey, Arango, Graeme, Kouaouci, Pellegrino, \& Taylor, 2000). Bajo el enfoque de la nueva economía de las migraciones laborales, la migración es vista como una estrategia familiar orientada a la diversificación de fuentes de ingreso y la minimización de los riesgos asociados a las fallas del mercado (Massey et al., 2000). Esta perspectiva teórica explicaría que, como consecuencia de la pérdida de atractivo migratorio de los grandes centros urbanos ocurrida en la década de los ochenta, la migración internacional se posicionó como una estrategia de acumulación de capital más efectiva que la migración interna (Lindstrom \& Lauster, 2001).

Una vez que los desplazamientos migratorios han iniciado en una determinada región, las condiciones en que se toma la decisión de emigrar se ven influenciadas 
por cambios en el contexto personal, restricciones y entorno socioeconómico inmediato. De esta manera, el enfoque conocido como causalidad acumulada da cuenta de la perpetuación del fenómeno migratorio (Massey, 1990). El conjunto de lazos interpersonales que conectan a migrantes y no migrantes en los lugares de origen y destino, llamados redes migratorias, brindan otro enfoque teórico que permite explicar la perpetuación de los movimientos migratorios mediante la disminución de costos y riesgos del desplazamiento e incrementando los rendimientos netos esperados (Massey et al., 200). Desde ambas perspectivas, los lazos que los migrantes tengan en los destinos migratorios serán más determinantes que la expectativa de mejorar las condiciones económicas. Además, los cambios negativos en la ganancia que se obtendría como resultado de la migración afectarán más a los individuos con redes pobres o de incorporación reciente a la dinámica migratoria (Lindstrom \& Lauster, 2001).

\section{Selectividad migratoria}

En el estudio de la dinámica migratoria se han identificado algunas características que permiten diferenciar a las poblaciones migrantes de las no migrantes. Esta selectividad migratoria se ha documentado en términos de edad, género, capital humano y social, entre otros. De todas estas, una dinámica específica por edad es la regularidad más frecuentemente encontrada entre los migrantes. Esta variable señala por sí misma las etapas del ciclo de vida y sus transiciones asociadas, como la asistencia escolar, la entrada a la adultez y al mercado de trabajo, y la formación familiar, entre otras (White \& Lindstrom, 2005).

La investigación sobre la selectividad de sexo presenta evidencia suficiente para no generalizar sobre los patrones migratorios. La mayor participación de personas de uno u otro sexo ha mostrado patrones opuestos, dependiendo de la sociedad y el periodo del desarrollo en que se ubican (Balán, 1983). De esta manera, mientras que muchos flujos rural-urbanos han sido predominantemente masculinos en naciones de África y sur de Asia, en muchos países de América Latina se observa una mayor presencia femenina (Rodríguez, 2004; Sobrino, 2010). Esta dinámica regional está asociada a las oportunidades laborales para las mujeres en los centros urbanos, pero también a la formación y reunificación familiar (Curran, Shafer, Donato, \& Garip, 2006; Mincer, 1978).

La migración también ha sido identificada como diferencial con base en el capital humano con el que cuentan los migrantes. En esta relación, los diferenciales por escolaridad y ocupación, desde una perspectiva económica, tienen como resultado mayores retornos que desplazamientos migratorios entre quienes cuenten 
con mayor escolaridad o habilidades fácilmente transferibles en el mercado de destino (White \& Lindstrom, 2005).

Algunos estudios identificaron otro tipo de selectividad con base en dos corrientes migratorias diferenciadas con origen en localidades rurales: una migración directa a grandes centros urbanos de México y otra hacia los destinos internacionales (Lozano-Ascencio, Roberts, \& Bean, 1996). Estos desplazamientos a diferentes destinos podrían ser interpretados como la existencia de alternativas migratorias (internas o internacionales) para la población rural de México. De esta manera, Lozano-Ascencio, Roberts y Bean (1996) encuentran que los destinos de los migrantes son determinados por las redes en que los individuos se encuentran inmersos, sus características sociodemográficas y las condiciones económicas de los lugares de origen y destino. Así, Sobrino (2010) observa que la disminución en la intensidad migratoria interna podría ser explicada por el incremento de la migración internacional, que surgió en décadas recientes como una alternativa más atractiva gracias a los lazos familiares y sociales que los migrantes han creado. Asimismo, la perspectiva de un mejor nivel de vida en Estados Unidos podría ser un factor determinante entre los migrantes dispuestos a enfrentar mayores riesgos durante el desplazamiento (Partida \& Matínez, 2006).

\section{Panorama general de las migraciones en México}

La migración interna ha sido considerada como el principal determinante demográfico de los cambios en la distribución territorial de la población de México durante el siglo XX (Partida, 2001). A lo largo de estos años se generaron sistemas duales impulsados por el modelo ISI y la diferenciación de polos campo-agricultura y ciudad-industria que impulsaron la pertinencia de la migración campo-ciudad con dirección a los grandes polos de desarrollo ${ }^{1}$ (Rodríguez \& Busso, 2009). Más adelante, cuando el modelo de desarrollo giró hacia la exportación, dejaron de existir los polos claramente diferenciados y surgieron múltiples alternativas territoriales. Es así que algunos estados de la frontera norte del país cobraron relevancia como lugares de destino, con la instalación en ellos de importantes centros de maquila (Partida, 2010).

A pesar de lo anterior, las recurrentes crisis de las década de los ochenta y la inestabilidad de los noventa motivaron una menor movilidad interna, puesto que disminuyeron las expectativas laborales y aumentaron los obstáculos asociados al costo del desplazamiento (Sobrino, 2010). Sin embargo, la migración interna

1 Distrito Federal, Monterrey en Nuevo León y Guadalajara en Jalisco. 
continuó estando fuertemente influenciada por la concentración de población y fuentes de empleo en algunos estados del país. De esta manera, la Ciudad de México y el Estado de México han logrado mantener la supremacía como lugares de destino de los flujos migratorios, impulsados de manera notable por la relevancia de la zona metropolitana del Valle de México (Partida, 2010).

Como resultado de los cambios en los patrones migratorios en el interior del país, las características de los migrantes también han cambiado. Históricamente, en América Latina se ha observado de manera recurrente una mayor predisposición femenina a participar en los desplazamientos internos, misma que se ha atribuido primordialmente a la importancia del flujo rural-urbano y a los espacios laborales específicos que ocupan las mujeres migrantes en las ciudades en el sector de servicios y el empleo doméstico (Rodríguez, 2004; Rodríguez \& Busso, 2009). En el caso mexicano, la cantidad de mujeres que había emigrado dentro del país superaba en aproximadamente $10 \%$ a la de los hombres a finales del siglo XX; sin embargo, en tiempos recientes tal supremacía ha disminuido ligeramente (Chávez, 1999). Este cambio en la participación femenina en la migración interna ha estado vinculado con otros cambios sociales ocurridos en el país; en particular, con cambios en la división sexual del trabajo, modelos de desarrollo y demográficos (Szasz, 1999). De manera particular, la mayor participación de mujeres en esta migración en la segunda mitad del siglo pasado se debió principalmente a la importancia relativa de los desplazamientos campo-ciudad de mujeres jóvenes por motivos laborales, sobre todo para insertarse como trabajadoras del hogar o trabajadoras manuales en los grandes centros urbanos (Szasz, 1994). Sin embargo, la creciente incorporación de las mujeres en los mercados de trabajo urbanos vinculados con el proceso de urbanización del país ha tenido como resultado una menor participación relativa de la población económicamente activa de mujeres migrantes internas (Partida, 2001).

La migración implica el costo de traslado del individuo, de los familiares a cargo y, en algunos casos, de sus pertenencias; por esta razón es más probable que emigren las personas solteras que las casadas y con hijos (Ebanks, 1993; Rodríguez \& Busso, 2009). Asimismo, no todos los integrantes del hogar presentarán la misma propensión a emigrar, el rol asignado a cada uno de los miembros del núcleo familiar será decisivo al momento de elegir un tipo de desplazamiento y el destino de este.

Hay argumentos sólidos para sostener que la escolaridad tiene un nexo positivo con la migración porque brinda información y habilita el desplazamiento; si la migración está asociada a profesiones y trayectorias laborales que requieren movilidad, se vincula positivamente con los ingresos (Rodríguez \& Busso, 2009). En México, las diferencias en los niveles de escolaridad entre las poblaciones migrantes y las no migrantes no solo son evidencia del distinto capital de cada uno de estos 
grupos, sino de un desarrollo desigual en el país. De esta manera, las principales zonas de destino en los noventa captaban inmigrantes con más altos niveles de escolaridad que la población nativa, con excepción de la Ciudad de México, entidad con población de alta escolaridad (Chávez, 1999).

La situación laboral es otro factor que explica las migraciones. El desempleo es, por definición, un factor impulsor de migración; sin embargo, hay que tomar en cuenta que los desplazamientos migratorios involucran costos financieros que pueden ser más difíciles de solventar para una persona desempleada (Rodríguez \& Busso, 2009). Entonces, es probable que emigren personas que cuentan con empleo garantizado en el destino o que hayan estado laborando durante un tiempo considerable en los lugares de origen.

México es un país con una importante tradición migratoria a Estados Unidos. Si bien la relación migratoria entre los dos países está enmarcada en la continuidad del fenómeno, también destaca por presentar cambios importantes en distintos momentos históricos (Corona \& Tuirán, 2001). El inicio de la dinámica migratoria entre ambas naciones surge con la conformación de los límites nacionales, pero a pesar de que históricamente los mexicanos habían emigrado a Estados Unidos, los flujos migratorios importantes comenzaron de manera significativa a partir de los conflictos revolucionarios de los inicios del siglo XX (Alba, Castillo \& Verduzco, 2010). Posteriormente, entre 1942 y 1964, el Programa Bracero marcó el inicio de una nueva etapa en la emigración mexicana con la exportación de mano de obra de comunidades rurales a Estados Unidos en un patrón de legalidad, circularidad, masculinidad y ruralidad (Tuirán \& Ávila, 2010). Una vez terminado el programa, la necesidad de contratar trabajadores mexicanos persistió, por lo que se produjo otra modalidad en la emigración mexicana: los trabajadores atravesaron la frontera sin documentos y se convirtieron en trabajadores indocumentados (Chávez, 1999).

En 1986, con la IRCA como un intento de regular la inmigración a Estados Unidos, surgieron políticas restrictivas que coadyuvaron significativamente a la pérdida de efectividad de los mecanismos que habían caracterizado a la migración mexicana y el cambio hacia una modalidad de migración de carácter más permanente (Leite et al., 2009). El endurecimiento de las medidas de seguridad en Estados Unidos, iniciado en 1994 con la Operación Guardián (Operation Gatekeeper) en California, reforzado después de los atentados del 11 de septiembre de 2001, la condición de indocumentados de millones de migrantes ha sido criminalizada (Nevins, 2010). Si bien la intención de las políticas de control fronterizo buscaban disuadir a los migrantes, la consecuencia inesperada ha sido el alargamiento de la estancia en Estados Unidos y el no retorno (Durand, 2016). Este carácter más restrictivo de la migración a ese país provocó un cambio significativo en el patrón 
migratorio mexicano, pues surgió uno de alcance nacional en México, más permanente, familiar, más urbano y con una composición ocupacional y socioeconómica muy diferenciada (Tuirán \& Ávila, 2010).

Caracterizada en sus orígenes por incluir a hombres jóvenes de localidades rurales y de algunas regiones específicas del país (Guanajuato, Michoacán y Jalisco), la migración internacional de mexicanos ha incorporado a poblaciones de cada vez más distintos orígenes. En México, muchos lugares de origen de los migrantes se han diversificado al añadir flujos migratorios de casi todos los estados del país, aunque persisten variaciones que hay que tener en cuenta (Verduzco, 2010). Otra modificación del patrón migratorio es la creciente participación de migrantes procedentes de áreas urbanas, tanto de las grandes zonas metropolitanas como de las llamadas ciudades intermedias; estas, además de absorber un porcentaje importante de los migrantes internos, sirven de plataforma para la migración a Estados Unidos (Corona \& Tuirán, 2001).

Además de los cambios en patrones geográficos, la migración los ha tenido en los perfiles sociodemográficos de los individuos que conforman este fenómeno. Destaca la creciente participación de las mujeres en los desplazamientos internacionales, vinculada con la transformación de su papel en la sociedad, lo que se expresa en su incorporación a situaciones, acciones o circunstancias antes no contempladas (Chávez, 1999). Asimismo, si bien es cierto que los niveles de escolaridad entre los migrantes mexicanos han mostrado tendencias crecientes, esto es consecuencia directa de incrementos en la escolaridad de la población general del país, principalmente a partir de la década de los setenta (Martínez, 2002). Por ello se observa que los mexicanos con educación media presentan mayor propensión a emigrar que poblaciones sin escolaridad — sin recursos para hacerlo- y con escolaridad superior - quienes tienen mejores condiciones de vida en México (Lowell, 2006). En Estados Unidos, si bien los migrantes mexicanos continúan mostrando bajos niveles de escolaridad, la creciente atracción de profesionistas calificados también ha quedado de manifiesto al incrementarse de manera considerable la presencia de migrantes con estudios superiores en años recientes (Leite et al., 2009; Lowell, 2006).

Como consecuencia de los cambios en los niveles de capital de la población, la diversificación ocupacional y sectorial de los migrantes ha cambiado tanto en México como en Estados Unidos. No solo se trata actualmente de población que en sus comunidades de origen se dedica a las actividades agropecuarias. Como consecuencia de una mayor migración urbana, otras actividades productivas han cobrado relevancia en la composición de los flujos migratorios. Esta redistribución de los mexicanos en más ocupaciones y sectores industriales en Estados Unidos también fue impulsada por la creciente posibilidad de movilidad ocupacional que millones 
de migrantes mexicanos tuvieron al ser beneficiados por la IRCA. De esta manera, en las últimas décadas del siglo pasado la importancia relativa del trabajo agrícola disminuyó, a la vez que el trabajo en industrias como la construcción y los servicios se incrementaba considerablemente, pues captaba a casi la mitad de los migrantes mexicanos ocupados en Estados Unidos antes de la recesión de 2007-2008 ( Leite et al., 2009). Esta recesión económica afectó particularmente aquellos sectores que empleaban mano de obra mexicana y tuvo como resultado una reducción de migrantes que generalmente se ocupaban en dichos sectores y el consecuente incremento aparente de migrantes más calificados, quienes se vieron menos afectados por la recesión económica (Villarreal, 2014).

Pocos estudios han analizado los cambios en las características demográficas de los migrantes de retorno de Estados Unidos. En un análisis de quienes retornaron hasta 2010, Masferrer y Roberts (2012) encontraron que estos se dirigían principalmente a la región fronteriza y algunos estados que no habían tenido altas tasas de emigración a Estados Unidos. Asimismo, estos autores encuentran una muy alta participación masculina y de jefes de hogar entre los migrantes retornados.

El panorama anterior da cuenta de diversos cambios en los perfiles migratorios de los individuos involucrados en la migración interna, internacional y de retorno. Dichos cambios han modificado los perfiles migratorios en relación con los lugares de origen y las características sociodemográficas de los migrantes. En general, la mayor importancia relativa de las zonas urbanas en ambos tipos de migración podría implicar una mayor dificultad para identificar un tipo de migración con un perfil demográfico y socioeconómico específico, puesto que el origen urbano de más migrantes daría como resultado de manera directa poblaciones con más altos niveles de escolaridad, creciente importancia de trabajadores en el sector servicios y configuraciones familiares similares.

En el presente análisis identifico las principales características demográficas de los migrantes internos, los emigrantes a Estados Unidos y los migrantes de retorno de ese país para el periodo 1990-2015. En particular, me interesa conocer si la selectividad en uno u otro tipo de migración ha cambiado durante los años en estudio y, de esta manera, poder identificar si las poblaciones involucradas en los desplazamientos migratorios son distintas.

\section{Métodos y datos}

La estrategia metodológica consistió en la identificación de grupos entre la población con algún tipo de experiencia migratoria con base en sus perfiles sociodemo- 
gráficos mediante el uso de técnicas multivariadas. En la primera parte se analizan las características de cada tipo de migrante en estudio en los años correspondientes, y en la segunda de las relaciones existentes entre las distintas variables relevantes en el estudio de las migraciones mexicanas y los distintos tipos de migraciones para el periodo 1990-2015.

La información sobre las características de los migrantes internos y de retorno proviene de las muestras de los censos de población y vivienda de 1990, 2000 y 2010 , así como de la Encuesta Intercensal 2015. Las muestras de los censos fueron obtenidas del Minnesota Population Center-IPUMS International (Minnesota Population Center, 2017) y la muestra de la Encuesta Intercensal se obtuvo directamente del Instituto Nacional de Estadística y Geografía (INEGI, 2015). La información sobre los emigrantes a Estados Unidos se obtuvo de la muestra del $5 \%$ de los censos de población de Estados Unidos para los años 1990 y 2000, así como de la American Community Survey de 2010 y 2015 mediante IPUMS-USA (Minnesota Population Center, 2017; Ruggles, Genadek, Goeken, Grover, \& Sobek, 2015).

Para el estudio de las características sociodemográficas se presenta un análisis descriptivo de las variables en estudio para la obtención del perfil de cada tipo de migrante en relación con sexo, edad, jefatura de hogar, condición de unión, escolaridad y sector de ocupación, región de residencia, tamaño de localidad, condición de habla de inglés y ciudadanía. Dado que las muestras fueron obtenidas de distintos ejercicios estadísticos, muchas de las categorías tuvieron que ser reagrupadas en conjuntos que permitieran la comparación a través del tiempo y para los distintos países. Para tal fin, se tomó la información contenida en el sitio IPUMS-International y en INEGI relativa a la clasificación industrial, así como la tabla de equivalencias educativas de la Secretaría de Educación Pública (SEP, s.f.).

En la segunda sección, usando un análisis de correspondencias múltiples (ACM), busco identificar cambios en la importancia relativa de cada característica demográfica en los distintos tipos de migración a través de los años analizados. El ACM es similar a otras técnicas de reducción de dimensiones, pero permite libremente el uso de datos categóricos, lo que posibilita un mejor análisis que otros métodos multivariados (Greenacre \& Blasius, 2006). Para esto, el ACM utiliza la distancia chicuadrada para estimar la similitud y la diferencia entre las categorías de una tabla cruzada, tomando en consideración las diferencias en los tamaños de las poblaciones involucradas en cada variable (Greenace \& Blasius, 1994). Con $p_{i j}$ como el valor observado en el renglón $i$ y la columna $j$ de la tabla cruzada; $r_{i}$ es el total de observaciones por renglón y $c_{j}$ es el total de observaciones por columna. Por ejemplo, si se desea calcular la distancia entre la modalidad migratoria y sexo para migrantes de retorno y mujeres, $p_{i j}$ representaría el cruce de dos características de las variables 
(i.e., migrante de retorno y mujer), $r_{i}$ el total de una categoría en una variable (i.e., migrantes de retorno) y $c_{j}$ el total de otra categoría en la segunda variable (i.e., mujer).

$$
d=\sqrt{\sum_{j=1}^{j}\left[\frac{p_{i j}}{r_{i}}-\frac{p_{i^{\prime} j}}{r_{i^{\prime}}}\right]^{2} / c_{j}}
$$

El ACM asume que las filas y columnas de una matriz de datos son puntos en un espacio euclidiano multidimensional y busca redefinir las dimensiones de forma tal que las primeras $n$-dimensiones nuevas capturen la mayor varianza posible. De manera similar a otras técnicas multivariadas, el ACM se basa en la descomposición de matrices normalizadas y centradas ${ }^{2}$, proporcionando así eigenvalores para seleccionar el número de dimensiones apropiadas. Esta técnica permite visualizar relaciones existentes entre las diferentes modalidades migratorias y las categorías contenidas en las demás variables. Cabe señalar que el uso de la ACM es de índole descriptiva, no inferencial, por lo que las relaciones observadas representan solamente una aproximación exploratoria al fenómeno. Asimismo, dado que las distancias entre las distintas categorías en el ACM pueden ser interpretadas como distancias euclidianas, es posible señalar qué características están más "cercanas" a cada tipo de migración. En esta segunda parte solo se utilizan las variables que permiten comparar entre grupos; es decir, aquellas que son observadas para todos los tipos de migración en el análisis. Por tal motivo se excluyen la región de residencia, el tamaño de localidad, la ciudadanía y el dominio del inglés.

En el análisis efectuado se distinguieron tres tipos de migraciones: interna, de retorno y emigración a Estados Unidos. Dado que algunas características están altamente asociadas a la etapa del ciclo de vida — como la edad, escolaridad y participación laboral-, el análisis se restringió a los individuos de 15 a 85 años de edad. De esta manera, las poblaciones finales en el análisis fueron definidas en la siguiente forma:

1. Migrantes internos. Población de 15 a 85 años nacida en México cuyo lugar de residencia cinco años antes correspondía a una entidad federativa diferente de aquella donde se encuentra viviendo.

2. Migrantes internacionales de retorno de Estados Unidos. Población de 15 a 85 años nacida en México que declara que cinco años antes residía en Estados Unidos.

3. Emigrantes a Estados Unidos. Población de 15 a 85 años residente en Estados Unidos, nacida en México y que lleva menos de cinco años viviendo en dicho país.

2 Se usa la matriz de Burt, que es simétrica y está formada por todos los cruces posibles entre variables. 


\section{Resultados}

Los tres tipos de migración presentaron cambios importantes entre 1990 y 2015. La migración interna creció considerablemente entre 1990 y 2000, para después reducirse gradualmente. La migración de retorno presentó un crecimiento importante hasta 2010, cuando 755 mil migrantes regresaron a México de Estados Unidos; sin embargo, en 2015 este tipo de migración incluyó a poco más de 408 mil personas. Por su parte, la emigración de mexicanos a Estados Unidos, registrada por las fuentes estadounidenses, tuvo un incremento considerable de 1990 a 2000, cuando se duplicó, pero ha mostrado una tendencia a la baja desde entonces.

GRÁFICA 1. Volumen de migrantes por tipo de migración y año, 1990-2015

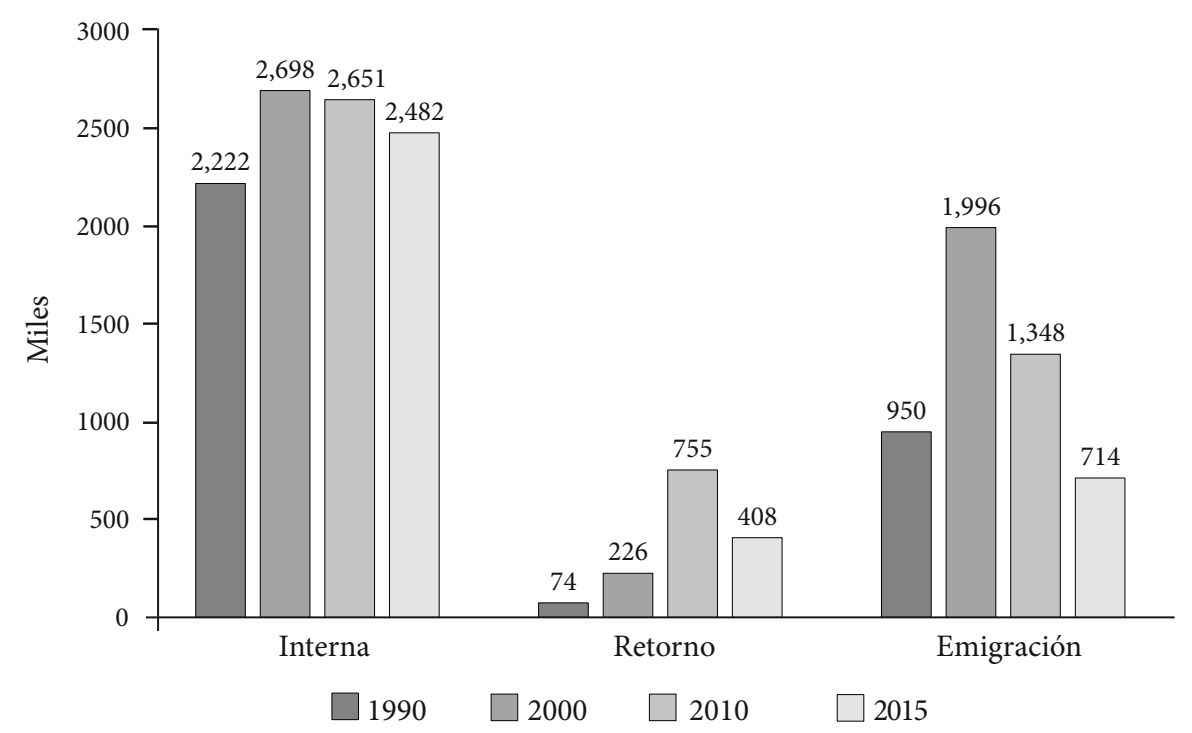

Fuente: Estimaciones propias con base en IPUMS-USA e INEGI, varios años.

El cuadro 1 contiene información sobre las variables demográficas y socioeconómicas de las poblaciones en estudio. Entre los migrantes internos, la participación femenina representa poco más de $50 \%$, misma que se ha mantenido relativamente constante entre 1990 y 2015. De igual manera, la participación en la migración interna de individuos menores de 30 años continúa siendo la norma, aunque desde 2010 dejaron de representar la mayoría de estos desplazamientos. Este tipo de migración continúa mostrando un carácter muy familiar, con más de $75 \%$ de migrantes como jefes de hogar, cónyuges o hijos e hijas. Asimismo, este tipo de 


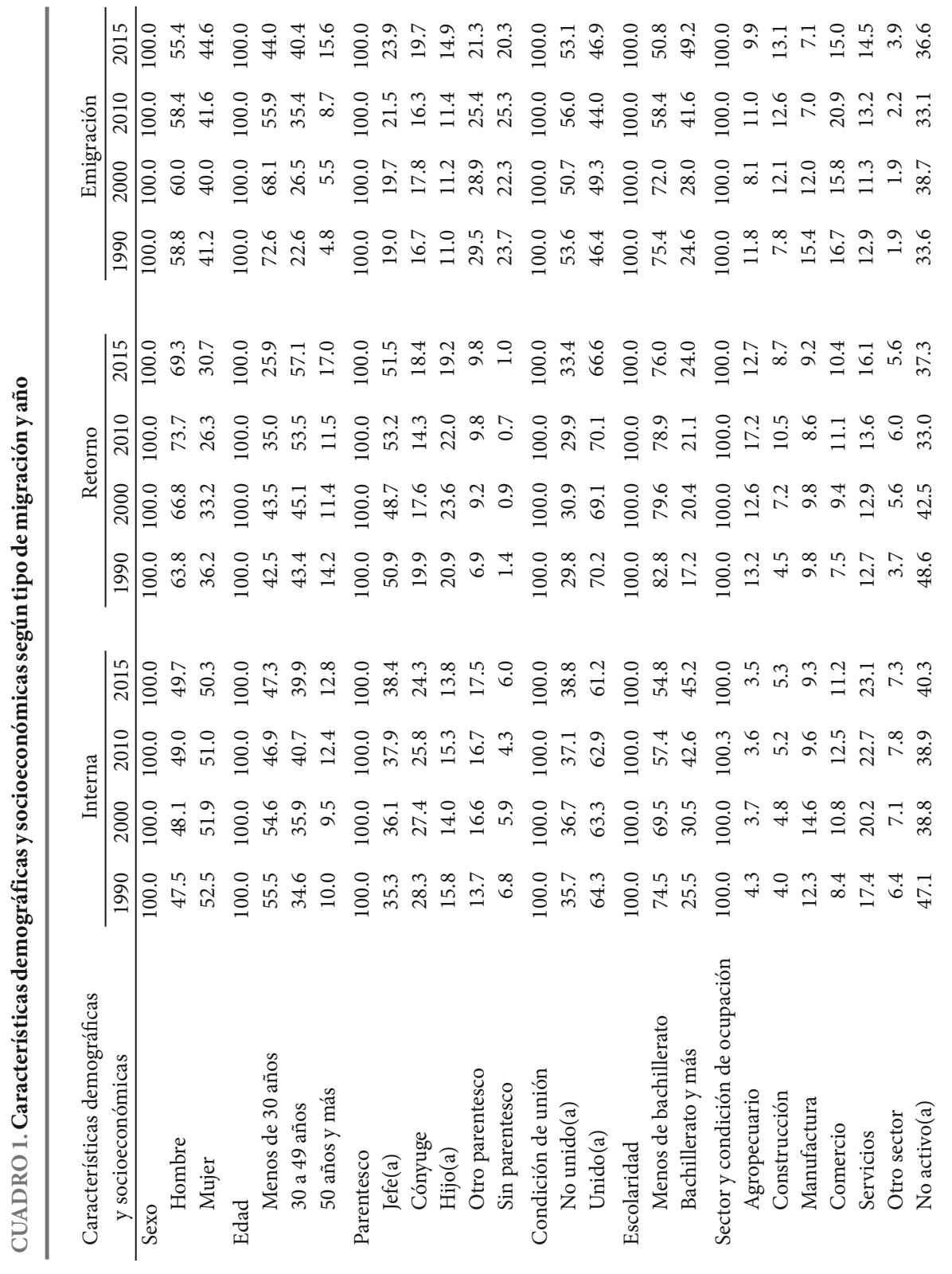




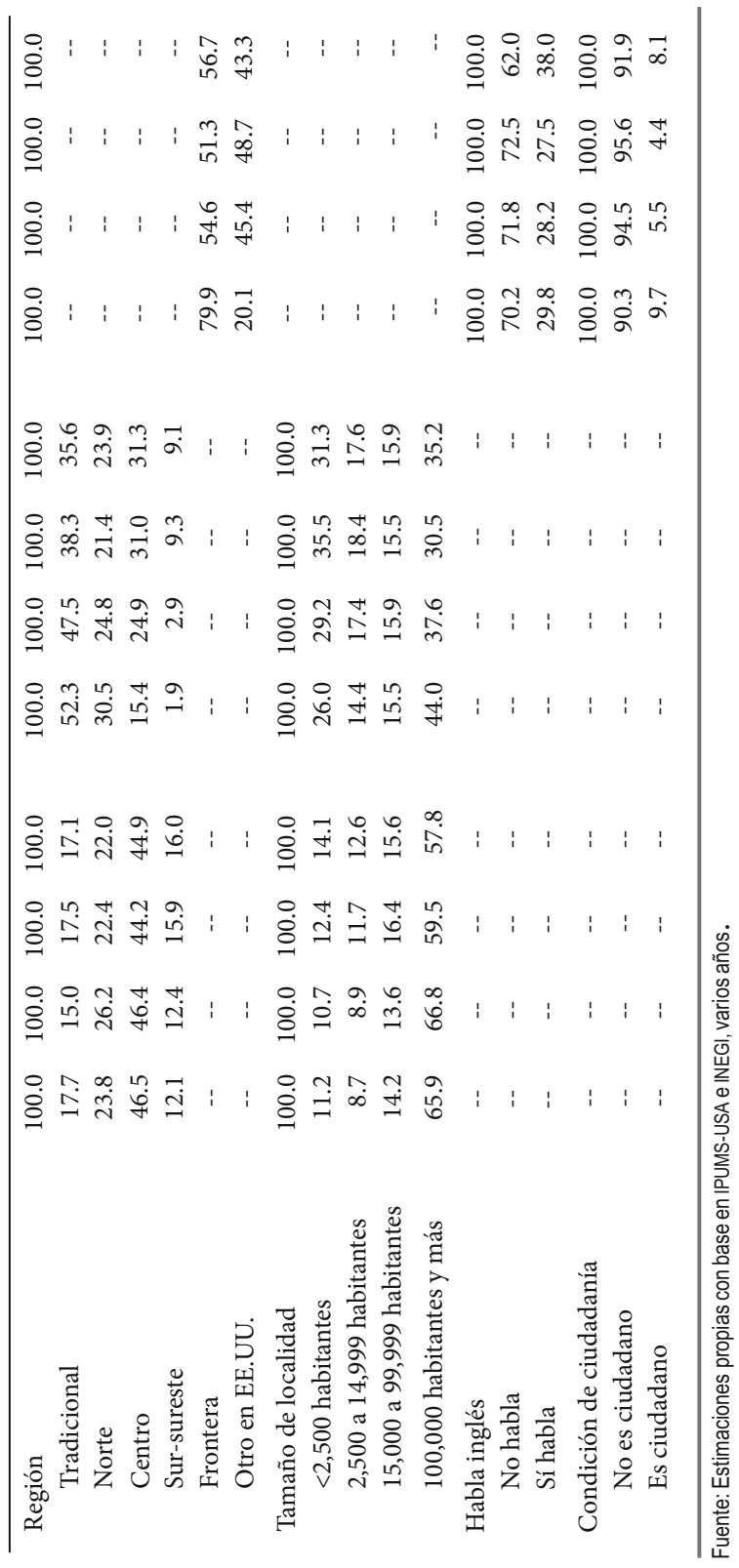


migración se ha visto acompañada de incrementos importantes de la participación de personas con mayores niveles de escolaridad y la creciente presencia de personas ocupadas en el sector servicios. Finalmente, la migración interna se sigue dirigiendo fuertemente hacia la región centro del país y a centros urbanos, aunque en 2010 y 2015 se observó una creciente participación de la región sur-sureste y de ciudades pequeñas y algunos centros rurales.

Entre los migrantes de retorno se ha tenido históricamente una mayor participación masculina, lo cual es respaldado por los datos obtenidos. En particular, los hombres representaron una proporción mayor en 2010 que en otros años. También se observa un notable incremento de emigrantes retornados de mayor edad en 2010 y un importante envejecimiento para 2015. Asimismo, destaca la mayor presencia de jefes de hogar entre los retornados en 2010. Al igual que con la migración interna, los migrantes retornados muestran mayores niveles de escolaridad en años más recientes; sin embargo, aún presentan importantes contingentes que se desempeñan en actividades agropecuarias y en la construcción. Destaca también en la migración de retorno la creciente importancia relativa de las regiones centro y sureste del país.

Entre los emigrantes recientes a Estados Unidos, la mayor participación masculina sigue siendo la norma. Sin embargo, los jóvenes, que representaban más de $70 \%$ en 1990, en 2015 representaron $44 \%$ del total, principalmente debido al incremento significativo de personas de mayores edades en esta población desde 2010. Esto podría estar asociado a un carácter más nuclear en la migración, ejemplificado en la reducción de aquellos que señalaban algún parentesco "lejano" con los jefes de hogar, pero también la reducción de quienes no están emparentados. Entre estos migrantes destaca un incremento muy importante de quienes cuentan con bachillerato, particularmente desde 2010, así como su mayor participación en actividades de comercio y servicios. Además, entre los nuevos migrantes hay un mayor porcentaje de hablantes de inglés en años recientes, así como una mayor dispersión geográfica en Estados Unidos.

Estos resultados descriptivos permiten identificar patrones asociados a distintas etapas de los procesos migratorios. Si bien la migración interna no presenta cambios considerables más allá de los asociados a la dinámica demográfica mexicana, los migrantes de retorno y emigrantes recientes tienen características cambiantes relacionadas, entre otras cosas, con el incremento en el retorno de migrantes después de la recesión de 2008-2009 y el endurecimiento de los controles fronterizos (Masferrer \& Roberts, 2012).

El uso del ACM muestra qué tan "cercanas" están las distintas categorías de las variables demográficas y socioeconómicas de cada condición migratoria en el análisis. La elección del número de dimensiones por analizar se basa en el porcentaje de la inercia (o varianza) explicada por cada una de estas. Generalmente se analizan 
aquellas dimensiones que contribuyan de manera significativa a la explicación de la varianza (10\% por lo general). En el presente análisis se eligieron dos dimensiones que en conjunto explicaron entre $62.5 \%$ y $71.2 \%$ de la varianza en los distintos años. ${ }^{3}$

CUADRO 2. Porcentaje de varianza explicada por las dimensiones

\begin{tabular}{crrrr}
\multirow{2}{*}{ Dimensión } & \multicolumn{5}{c}{ Año } \\
\cline { 2 - 5 } & 1990 & 2000 & 2010 & 2015 \\
\hline 1 & 42.71 & 44.27 & 36.86 & 32.97 \\
2 & 28.50 & 24.80 & 28.94 & 29.57 \\
3 & 2.41 & 3.07 & 5.14 & 5.99 \\
4 & 1.61 & 1.96 & 2.96 & 2.66 \\
5 & 0.23 & 0.54 & 0.89 & 0.94 \\
6 & 0.08 & 0.12 & 0.03 & 0.08 \\
7 & 0.01 & 0.03 & 0.00 & 0.01 \\
8 & 0.00 & 0.00 & 0.00 & 0.00 \\
Dims. 1 y 2 & 71.21 & 69.07 & 65.80 & 62.54
\end{tabular}

Fuente: Elaboración propia.

Una vez seleccionadas las dimensiones, contribuciones y cargas de cada una de las categorías de las variables, se pueden utilizar como coordenadas en cada uno de los ejes (categorías) y visualizar las distancias entre estas. El análisis de las distancias usando ACM es de naturaleza descriptiva, por lo que no es afectado por el tamaño de las muestras utilizadas sino por las frecuencias relativas (Le Roux \& Rouanet, 2010). La gráfica 2 contiene las nubes de categorías para los distintos años del análisis, las cuales muestran qué categorías están más cercanas a cada tipo de migración por año.

En todos los años considerados en el análisis es posible apreciar una serie de continuidades en las características migratorias. La migración interna tiende a ubicarse en el centro de la nube de categorías, mientras que la migración de retorno y la emigración se ubican en la periferia. La consistente localización de las categorías a lo largo de los años sugiere la persistencia de características conocidas entre los migrantes. Por ejemplo, la migración de retorno tiende a estar cercana a las categorías de hombres, jefes de hogar, entre los 30 y 49 años de edad; la emigración, a su vez, está más asociada a hombres jóvenes, solteros, hijos de los jefes de hogar o sin relación de parentesco, y la migración interna es más cercana a las mujeres, con importante presencia de aquellas de 50 y más años y mayor cercanía al sector servicios.

Los valores propios para las primeras dos dimensiones, $\lambda_{1}$ y $\lambda_{2}$, fueron: $1990 \lambda_{1}=0.2062, \lambda_{2}=0.1684$; $2000 \lambda_{1}=0.1862,12=0.1394 ; 2010 \lambda_{1}=0.1506, \lambda_{2}=0.0635 ; \mathrm{y} 2015 \lambda_{1}=0.1396, \lambda_{2}=0.0629$. 


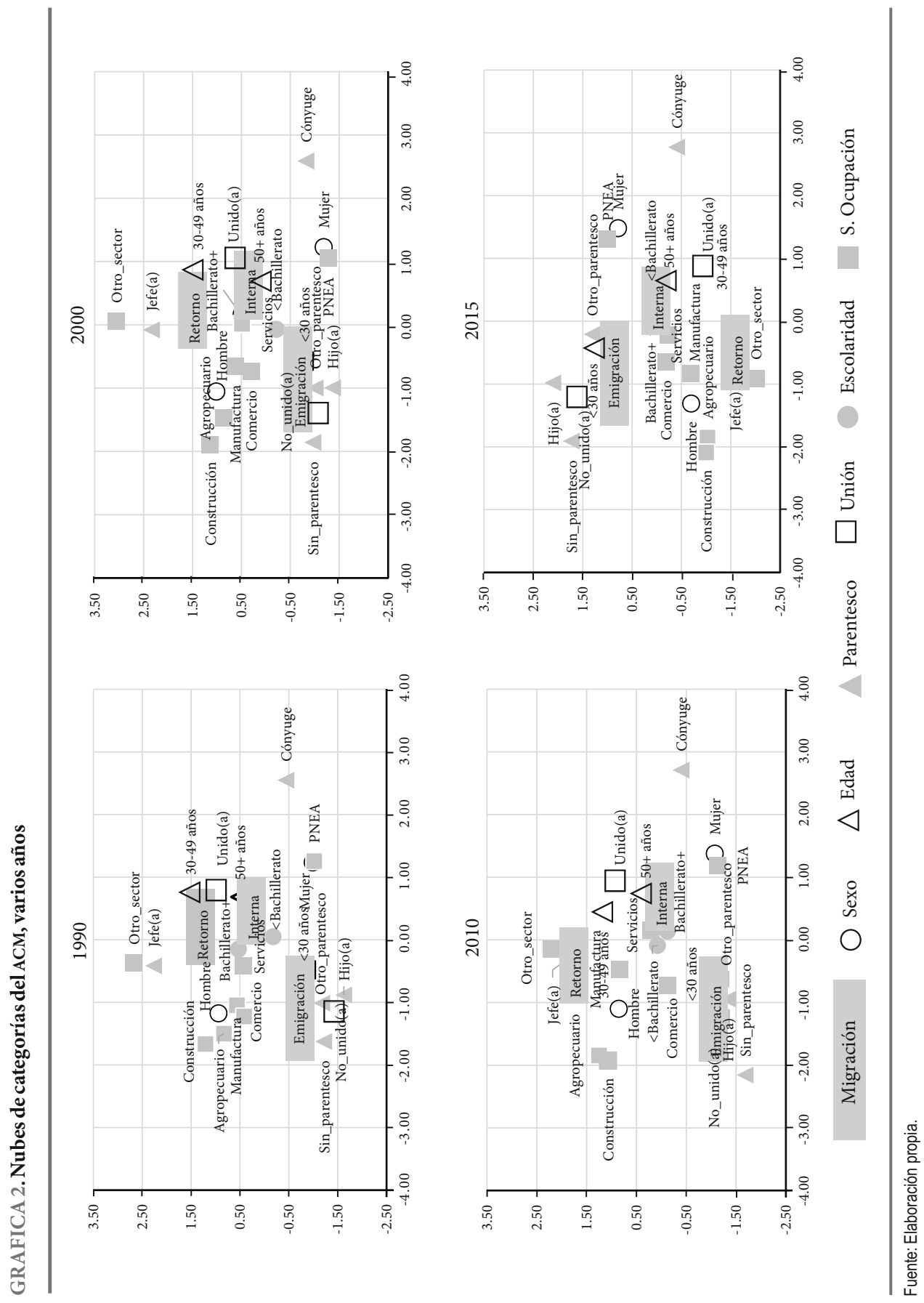


Para observar los cambios a lo largo de los años es posible usar las coordenadas obtenidas del ACM y estimar la distancia euclidiana entre los distintos puntos. El resultado de este ejercicio se presenta en el cuadro 3.

CUADRO 3. Distancia entre las coordenadas de las categorías según tipo de migración y año

\begin{tabular}{|c|c|c|c|c|c|c|c|c|c|c|c|c|}
\hline \multirow{2}{*}{$\begin{array}{l}\text { Características demográficas } \\
\text { y socioeconómicas }\end{array}$} & \multicolumn{4}{|c|}{ Interna } & \multicolumn{4}{|c|}{ Retorno } & \multicolumn{4}{|c|}{ Emigración } \\
\hline & 1990 & 2000 & 2010 & 2015 & 1990 & 2000 & 2010 & 2015 & 1990 & 2000 & 2010 & 2015 \\
\hline \multicolumn{13}{|l|}{ Migración } \\
\hline Interna & -- & -- & -- & -- & 1.07 & 1.21 & 2.04 & 1.80 & 1.84 & 1.80 & 2.09 & 1.42 \\
\hline Retorno & 1.07 & 1.21 & 2.04 & 1.80 & -- & -- & -- & -- & 2.41 & 2.43 & 2.90 & 2.47 \\
\hline Emigración & 1.84 & 1.80 & 2.09 & 1.42 & 2.41 & 2.43 & 2.90 & 2.47 & -- & -- & -- & -- \\
\hline \multicolumn{13}{|l|}{ Sexo } \\
\hline Hombre & 1.77 & 1.80 & 1.96 & 1.78 & 1.43 & 1.37 & 1.14 & 1.21 & 1.67 & 1.68 & 1.90 & 1.96 \\
\hline Mujer & 1.47 & 1.66 & 1.31 & 1.39 & 2.51 & 2.87 & 3.35 & 3.09 & 2.34 & 2.16 & 2.48 & 2.30 \\
\hline \multicolumn{13}{|l|}{ Edad } \\
\hline Menos de 30 años & 1.47 & 1.65 & 1.67 & 1.47 & 2.27 & 2.42 & 2.86 & 2.91 & 0.63 & 0.32 & 0.56 & 0.46 \\
\hline 30 a 49 años & 1.28 & 1.07 & 1.16 & 1.33 & 0.57 & 0.67 & 1.03 & 0.76 & 2.89 & 2.70 & 2.70 & 2.45 \\
\hline 50 años y más & 0.33 & 0.22 & 0.29 & 0.34 & 0.93 & 1.43 & 1.80 & 1.71 & 2.16 & 1.74 & 2.25 & 1.94 \\
\hline \multicolumn{13}{|l|}{ Parentesco } \\
\hline Jefe(a) & 2.19 & 2.10 & 2.09 & 1.94 & 1.14 & 0.89 & 0.15 & 0.29 & 3.07 & 3.10 & 3.03 & 2.92 \\
\hline Cónyuge & 2.20 & 2.29 & 2.07 & 2.49 & 2.92 & 3.31 & 3.79 & 3.48 & 3.65 & 3.46 & 3.87 & 3.65 \\
\hline Hijo(a) & 2.32 & 2.36 & 2.13 & 2.46 & 3.13 & 3.12 & 3.14 & 3.72 & 0.93 & 0.72 & 0.32 & 0.33 \\
\hline Otro parentesco & 2.06 & 2.12 & 1.80 & 1.40 & 2.77 & 2.80 & 2.97 & 2.91 & 0.46 & 0.37 & 0.50 & 0.63 \\
\hline Sin parentesco & 2.56 & 2.81 & 3.32 & 2.81 & 3.12 & 3.23 & 3.87 & 3.61 & 0.72 & 1.04 & 1.23 & 1.26 \\
\hline \multicolumn{13}{|l|}{ Condición de unión } \\
\hline No unido(a) & 2.31 & 2.38 & 2.30 & 2.08 & 2.96 & 2.92 & 3.07 & 3.14 & 0.56 & 0.58 & 0.21 & 0.36 \\
\hline Unido(a) & 0.73 & 0.50 & 0.82 & 1.15 & 0.80 & 1.14 & 1.59 & 1.42 & 2.53 & 2.30 & 2.74 & 2.49 \\
\hline \multicolumn{13}{|l|}{ Escolaridad } \\
\hline Menos de bachillerato & 0.61 & 0.90 & 0.78 & 0.26 & 1.49 & 1.74 & 1.72 & 1.62 & 1.27 & 0.91 & 1.51 & 1.44 \\
\hline Bachillerato y más & 0.67 & 0.48 & 0.57 & 0.42 & 0.85 & 0.99 & 1.96 & 1.73 & 1.57 & 1.57 & 1.55 & 1.18 \\
\hline \multicolumn{13}{|l|}{$\begin{array}{l}\text { Sector y condición } \\
\text { de ocupación }\end{array}$} \\
\hline Agropecuario & 2.04 & 2.16 & 2.81 & 2.41 & 1.77 & 1.82 & 1.53 & 1.47 & 1.61 & 1.64 & 2.42 & 2.52 \\
\hline Construcción & 2.33 & 2.63 & 2.81 & 2.61 & 1.88 & 2.15 & 1.68 & 1.70 & 2.02 & 2.07 & 2.27 & 2.47 \\
\hline Manufactura & 1.54 & 1.31 & 1.41 & 1.35 & 1.46 & 1.24 & 0.94 & 0.95 & 1.29 & 1.31 & 1.98 & 1.88 \\
\hline Comercio & 1.69 & 1.36 & 1.43 & 0.99 & 1.69 & 1.54 & 1.92 & 1.41 & 1.15 & 0.97 & 0.99 & 0.94 \\
\hline Servicios & 0.89 & 0.62 & 0.57 & 0.59 & 1.08 & 1.04 & 1.64 & 1.38 & 1.34 & 1.45 & 1.78 & 1.40 \\
\hline Otro sector & 2.54 & 2.76 & 2.33 & 2.37 & 1.48 & 1.56 & 0.52 & 0.59 & 3.47 & 3.83 & 3.40 & 3.26 \\
\hline No activo(a) & 1.51 & 1.69 & 1.27 & 1.40 & 2.55 & 2.90 & 3.30 & 3.15 & 2.37 & 2.02 & 2.29 & 2.13 \\
\hline
\end{tabular}

Fuente: Elaboración propia.

Es posible afirmar que en 1990 el perfil de los migrantes internos y los migrantes de retorno fue más parecido que nunca y que en 2010 presentaron las mayores diferencias. Asimismo, la migración interna es hoy en día más similar en perfiles migratorios a la emigración a Estados Unidos, después de haber alcanzado una mayor 
diferencia en 2010. La migración de retorno y la emigración tienden a presentar importantes diferencias en los perfiles de los migrantes, indicado esto por la magnitud de los altos valores en distancias a lo largo del periodo en estudio. Sobresale en esta dinámica la distancia entre migración de retorno y emigración a Estados Unidos en 2010.

En el análisis de las relaciones entre los tipos de migración y las características demográficas y socioeconómicas se tiene interés en dos factores. Primero, cómo se comportan las distancias entre cada categoría y los distintos tipos de migración a lo largo de los años. Segundo, qué tan diferentes son las distancias de las categorías de las dimensiones demográfica y socioeconómica. De esta manera, sin importar la magnitud de las distancias, si ambas son similares entre categorías de la misma dimensión, se podría afirmar que dicha característica no representa una dimensión que discrimine por tipo de migración.

En este análisis se confirma la relativamente mayor cercanía de las mujeres a la migración interna y la mayor participación de hombres en migración de retorno y emigración. Cabe señalar que el año 2010 representa un punto importante en las diferencias de género en la participación en los diversos tipos de migración. En el caso de la migración interna, la distancia de los hombres fue casi $50 \%$ mayor que la de las mujeres, pero en la migración de retorno ellas se ubicaron casi tres veces más lejos que los hombres.

La migración interna es más cercana a individuos de 50 años y más, la de retorno a personas de 30 a 49 años, y la emigración a Estados Unidos es más cercana a jóvenes de menos de 30 años. También es posible observar patrones diferentes en lo relativo a la posición en el hogar de los migrantes. La migración interna está a distancias similares de las distintas posiciones en el hogar; es decir, este tipo de migración no discrimina por posición en el hogar. La migración de retorno es cada vez más cercana a los jefes de hogar. Por su parte, la emigración a Estados Unidos está más asociada a los hijos, otros parientes y aquellos sin parentesco con el jefe del hogar. En un contexto similar, la migración interna y la de retorno están más asociadas a personas unidas, mientras que la emigración se asocia más a aquellas que no están en unión.

El capital humano, medido en términos de escolaridad, parece no discriminar mucho entre los participantes en la migración interna. Sin embargo, es notorio que durante 2000 y 2010 los migrantes internos estaban más cercanos a individuos con mayor escolaridad, pero en 2015 la tendencia se revirtió. En la migración de retorno también se observa un cambio entre 2000 y 2010, pues en años más recientes los migrantes retornados están más asociados a menor escolaridad. Contrario a los casos anteriores, la emigración a Estados Unidos había estado vinculada a bajos niveles de escolaridad, pero en 2015 se revirtió la tendencia y ahora aquellos con bachillerato 
terminado son más cercanos a este tipo de migración.

La última categoría en este análisis corresponde al sector y la condición de ocupación. En este contexto, la migración interna es muy cercana a los sectores servicios y comercio. Por su parte, la migración de retorno incluye más a personas del sector manufacturero y a empleadas en comercio y actividades agropecuarias. Finalmente, entre los emigrantes a Estados Unidos destaca cada vez más la participación en comercio y servicios, así como la creciente distancia respecto a las actividades de los sectores agropecuario y de la construcción.

\section{Discusión y conclusiones}

En el presente análisis se buscaba identificar cambios en los perfiles de los migrantes involucrados en migración interna, de retorno y la emigración a Estados Unidos. Diversos cambios se han observado en los tres tipos de migración. Por ejemplo, para la migración interna Romo y Téllez (2013) observaron la pérdida de selectividad migratoria por sexo y la consistente mayor participación de personas en edades jóvenes. De igual manera, estos autores señalan que los migrantes internos tienden a ser altamente calificados y se concentran cada vez más en actividades del sector servicios. En la migración de retorno, en años recientes se había observado un importante incremento en la participación de hombres, jefes de hogar y de las regiones no tradicionales como destino (Masferrer \& Roberts, 2012). Finalmente, en lo concerniente a la emigración, está compuesta por una cada vez mayor proporción de mujeres, migrantes de mayor edad y con mejores credenciales educativas, en unión y cada vez más alejados de la región fronteriza (González-Barrera \& López, 2013).

Los resultados del presente análisis difieren de los hallazgos anteriores en que los migrantes no son comparados con la población no migrante, sino con ellos mismos en periodos anteriores y con otros migrantes mexicanos. Con base en los modelos de Zelinsky (1971) y Skeldon (1977), una vez que los países han alcanzado niveles altos de desarrollo, las migraciones internas comienzan a ser entre zonas urbanas y la migración internacional surge como alternativa. Sin embargo, en el caso mexicano la migración internacional tuvo sus orígenes en contextos rurales de la región occidente del país (Durand, 2016) y ha ido poco a poco abriéndose paso hacia los centros urbanos que han perdido su capacidad de atracción migratoria ante un contexto de expansión de redes familiares que facilitan el desplazamiento al extranjero (Sobrino, 2010). Si bien la naturaleza de la información utilizada en el presente análisis - consistente en datos de naturaleza transversal - no permite observar cambios en las preferencias migratorias de los individuos, el estudio de las características de las poblaciones migrantes representa una oportunidad de entender la participación de 
individuos con ciertas características en uno u otro tipo de migración, lo que señalaría qué tan distintas son estas.

En términos de volumen, la migración interna es la más común en el país, pues incorpora entre $55 \%$ y $69 \%$ del total de los migrantes mexicanos. A pesar de lo anterior, la dinámica migratoria interna mexicana es baja comparada con las de otros países de la región y presenta una tendencia a la baja (Bell \& Charles-Edward, 2013). Esta tendencia ha sido explicada por la reducción en el crecimiento económico de regiones tradicionalmente receptoras de migrantes, así como por la dinámica de otros componentes de crecimiento demográfico en México, que ejercen menor presión que en decenios anteriores (Sobrino, 2010). En el caso del componente internacional, destaca el fuerte crecimiento de la emigración de mexicanos a Estados Unidos entre 1990 y 2000 y la notable disminución en 2010 y 2015. Esta dinámica parece responder a mejoras en las condiciones económicas y sociales de México que han reducido el atractivo migratorio de Estados Unidos, y particularmente a la reducción en el número de empleos disponibles en dicho país (Pew Hispanic Center, 2011). Asimismo, el creciente énfasis en el control de las fronteras ha tenido como resultado una mayor permanencia de los migrantes en sus lugares de destino, lo cual desgasta la dinámica circular y de corta estancia que había caracterizado a la migración mexicana (Cornelius, 2005; Durand, 2016). En cuanto a la migración de retorno, mostró un importante crecimiento particularmente entre 2000 y 2010 y una ligera reducción en 2015. Sin embargo, observando la tendencia general, más que cambios significativos en 2015, los niveles de retorno alcanzados en 2010 parecen haber sido atípicos. Diversos análisis han observado que durante dichos años la migración de retorno fue motivada principalmente por la disminución en los puestos de trabajo disponibles como consecuencia de la recesión de 2008-2009, aunado a mayores controles migratorios y políticas de deportación masiva (Masferrer \& Roberts, 2012; Passel, Cohn, \& González- Barrera, 2012; Zenteno, 2012).

Así como ha cambiado el volumen de los distintos flujos migratorios, también lo han hecho las características de los migrantes. Sin embargo, al comparar los perfiles de los migrantes internos, de retorno y emigrantes fue posible observar no solo cambios sino la permanencia de algunas características. Uno de los rasgos más significativos de los tres tipos de migración analizados ha sido una marcada diferenciación por sexo. Los resultados del análisis muestran que las mujeres siguen estando más involucradas en la migración interna y los hombres en la internacional. Sin embargo, en el segundo de los casos, mientras que para la emigración a Estados Unidos la distancia entre hombres y mujeres ha disminuido, en la migración de retorno ha aumentado. Esto podría estar asociado a la mayor propensión que las mujeres migrantes han mostrado a emigrar de manera más permanente, ya sea como estrategia de reunificación familiar o como agentes independientes (Feliciano, 2008; Hondagneu-Sotelo \& 
Crandford, 1999). En el análisis también se observa la mayor cercanía de los hombres a la migración de retorno en 2010, misma que había sido identificada en la literatura y ha sido asociada al mayor impacto de la recesión económica en puestos de trabajo tradicionalmente masculinos (Masferrer \& Roberts, 2012; Villarreal, 2014).

La relación de la migración con la edad también se ha documentado con anterioridad. El presente análisis brinda una perspectiva comparada entre los tres tipos de migración. Es decir, si bien se conoce que la migración es más común en las edades en que se ingresa a los mercados de trabajo y durante la etapa de formación de una familia (Lindstrom \& López-Ramírez, 2010; Rogers \& Castro, 1982), el análisis aquí realizado permite contrastar los distintos tipos de migración. En este contexto, la migración interna tuvo mayor afinidad con la población de 50 años y más, la migración de retorno con individuos de 30 a 49 años y la emigración con los más jóvenes, menores de 30 años. Estos resultados refuerzan el hallazgo previo de que los emigrantes a Estados Unidos son identificados como jóvenes más dispuestos a enfrentar riesgos o en etapas iniciales de transición a la vida adulta (Kandel \& Massey, 2002; Lindstrom \& López-Ramírez, 2010).

Las diferencias de género y a lo largo del curso de vida entre los distintos tipos de migración están asociadas también a la posición de parentesco de los migrantes. La migración interna muestra un carácter mixto; por un lado, una naturaleza familiar, con distancias casi iguales para migrantes que declaran ser jefes, cónyuges o hijos, y por el otro, menores distancias para quienes se identifican como otro tipo de parientes de los jefes de hogar. Esta posición en el hogar, en conjunto con las edades avanzadas más vinculadas a la migración interna, indicarían que la migración en la vejez puede obedecer a la reunificación familiar y arreglos residenciales diversos para los adultos mayores que se encuentran de nuevo viviendo con sus hijos u otros familiares (Partida, 2000; Ramírez, 2008). Por su parte, la migración de retorno sigue estando más vinculada con migrantes que señalan ser jefes de hogar. Además, también es posible observar que 2010 representó un año atípico en que la migración de retorno estuvo fuertemente vinculada con esta posición en el hogar, que ya habían observado otros autores (Masferrer \& Roberts, 2012; Villarreal, 2014). Finalmente, la emigración a Estados Unidos se mantiene asociada a los hijos e hijas de los jefes de hogar, a personas con otro parentesco y aquellas sin relación de parentesco. La presencia de hijos en la migración ha sido documentada como una etapa de transición a la adultez y una estrategia familiar de diversificación de fuentes de ingreso (Cerruti \& Massey, 2001; Kandel \& Massey, 2002); al mismo tiempo, la presencia de otros familiares y personas no relacionadas muestra la importancia de las redes sociales en la migración a Estados Unidos (McKenzie \& Rapoport, 2007). En este mismo entorno, tal migración tiende a estar más asociada a personas que no están unidas, mientras que la 
migración interna y de retorno mostraron mayor cercanía a la condición de unión de los migrantes.

En términos de escolaridad, los migrantes internos no están tan diferenciados por esta característica; sin embargo, es importante señalar que en 2000 y 2010 aquellos con bachillerato y más estuvieron más asociados a este tipo de migración que en los otros años. Esta característica la habían observado con anterioridad Romo y Téllez (2013). La migración de retorno había incluido a personas con mayor escolaridad en 1990 y 2000, pero a partir del año 2010, aquellas sin bachillerato terminado estuvieron más asociadas al retorno. Esto quiere decir que el retorno incorpora a cada vez más migrantes con bajos niveles de capital humano, medido aquí por la escolaridad alcanzada. De manera contrastante, la emigración a Estados Unidos estuvo más vinculada a personas con escolaridad equivalente a bachillerato o superior a partir de 2015. En términos de capital humano, queda claro que la migración interna involucra a migrantes con diversos perfiles educativos, mientras que la escolaridad de los emigrantes se ha incrementado, a la vez que se ha reducido en los retornados.

Las condiciones y el sector de ocupación de la población mexicana permiten observar dos patrones muy diferenciados. Primero, México ha transitado cada vez más claramente a una economía basada en actividades del sector terciario. Segundo, los migrantes mexicanos en Estados Unidos se alejan cada vez más del perfil tradicional de migrantes empleados en actividades agropecuarias y de la construcción. Los migrantes internos mostraron cada vez mayor afinidad con actividades de los sectores comercio y servicios y mayor acercamiento al sector de la construcción. Los migrantes de retorno, por su parte, en años recientes se han concentrado más en la manufactura, el comercio y los servicios. Los cambios más importantes se pueden observar en los emigrantes a Estados Unidos; por un lado, se han disociado cada vez más del sector agropecuario, y a partir de 2010 también del sector de la construcción, mientras que se acercan más al comercio y los servicios. Esto se ha explicado como consecuencia de la recesión de 2008-2009, que afectó principalmente a la construcción, donde se concentraba una parte importante de la mano de obra mexicana en Estados Unidos (Leite et al., 2009; Villarreal, 2014).

En el presente análisis se buscó identificar cambios en las características de los migrantes mexicanos inmersos en la migración interna, de retorno y a Estados Unidos. A diferencia de otros análisis, en que se compara a migrantes con no migrantes, el presente trabajo contrastó estos tres tipos de migraciones durante el periodo 1990-2015. Mediante el uso del análisis de correspondencias múltiples fue posible identificar no solo factores asociados a cada tipo de migración, sino qué tan similares o diferentes son los perfiles de los migrantes inmersos en cada una de las modalidades en estudio. 
Finalmente, si bien cada tipo de migración continúa teniendo particularidades propias de la dinámica en que se encuentra inmersa, queda claro que muchos factores se han modificado. Por ejemplo, mientras que la migración interna muestra un carácter familiar, en el que participan individuos de todas las edades, también se asiste a una mayor participación relativa de adultos mayores y personas no económicamente activas. Por el contrario, la emigración a Estados Unidos presenta la tendencia a una mayor participación femenina, aún dominada por personas jóvenes, con mayor capital humano y en nuevos sectores de ocupación. En cuanto a la migración de retorno, algunos cambios observados en 2010 respecto a los años anteriores se habían revertido en 2015. Esto habla de las condiciones excepcionales que enmarcaron el retorno en el periodo 2005-2010, pero también de la rapidez con que los migrantes se adaptan a nuevas condiciones.

\section{Referencias}

Alba, F., Castillo, M. A., \& Verduzco, G. (2010). Introducción general. En Alba, F., Castillo, M. A., \& Verduzco, G. (coords.), Migraciones internacionales (Los grandes problemas de México, vol. III ). México: El Colegio de México.

Arango, J. (2003). La explicación teórica de las migraciones: luz y sombra. Migración y Desarrollo, 1(1), 4-22.

Balán, J. (1983). Selectivity of migration in international and internal flows. Buenos Aires. Bell, M. \& Charles-Edwards, E. (2013). Cross-national comparisons of internal migration: an update on global patterns and trends. Technical Paper No. 2013/1. New York. Recuperado de http://www.un.org/en/development/desa/ population/publications/pdf/technical/TP2013-1.pdf

Canales, A. \& Montiel, I. (2007, 16 de abril). De la migración interna a la internacional: en búsqueda del eslabón perdido. Presentado en el Taller Nacional sobre Migración Interna y Desarrollo en México: diagnóstico, perspectivas y políticas, El Colegio de México, México, D.F.

Cerrutti, M. \& Massey, D. S. (2001). On the auspices of female migration from Mexico to the United States. Demography, 38(2), 187-200. Recuperado de https://doi.org/10.1353/dem.2001.0013

Chávez, A. M. (1999). La nueva dinámica de la migración interna en México 19701990. Cuernavaca, Morelos: Centro Regional de Investigaciones Multidisciplinarias-Universidad Nacional Autónoma de México.

Cornelius, W. (2005). Controlling "unwanted" immigration: lessons from the United States, 1993-2004. Journal of Ethnic and Migration Studies, 31(4), 775-794. 
Corona, R. \& Tuirán, R. (2001). La migración internacional desde y hacia México. México: Consejo Nacional de Población, Fondo de Cultura Económica.

Curran, S. R., Shafer, S., Donato, K. M., \& Garip, F. (2006). Mapping gender and migration in sociological scholarship: is segregation or integration? International Migration Review, 40(1), 199-223.

Durand, J. (2016). Historia mínima de la migración México-Estados Unidos. México: El Colegio de México.

Ebanks, E. (1993). Determinantes socioeconómicos de la migración interna, con especial referencia a la región de América Latina y el Caribe. Santiago de Chile: Comisión Económica para América Latina y el Caribe, Agencia Canadiense para el Desarrollo Internacional.

Feliciano, C. (2008). Gendered selectivity: US Mexican immigrants and Mexican nonmigrants, 1960-2000. Latin American Research Review. Recuperado de http://www.jstor.org/stable/20488112

Fernández-Kelly, P. \& Massey, D. S. (2007). Borders for whom? The role of NAFTA in Mexico-U.S. migration. The Annals of the American Academy of Political and Social Science, 610(1), 98-118.

Gonzalez-Barrera, A. \& Lopez, M. (2013). A demographic portrait of Mexican-origin Hispanics in the United States. Washington: Pew Hispanic Center. Recuperado de http://www.pewhispanic.org/2013/05/01/a-demographic-portrait-of-mexicanorigin-hispanics-in-the-united-states/

Greenacre, M. \& Blasius, J. (1994). Correspondence analysis in the social sciences. San Diego: Academic Press.

Greenacre, M. \& Blasius, J. (2006). Multiple correspondence analysis and related methods. Boca Raton: Chapman y Hall/CRC.

Hondagneu-Sotelo, P. \& Crandford, C. (1999). Gender and migration. En Chafetz, J. S. (ed.), Handbook of the sociology of gender (pp. 105-126). New York: Kluwer Academic/Plenum Publishers, Springer Verlag.

Instituto Nacional de Estadística y Geografía (INEGI) (2015). Encuesta Intercensal 2015. Recuperado de http://www.inegi.org.mx/est/contenidos/Proyectos/ encuestas/hogares/especiales/ei2015/

Kandel, W. \& Massey, D. S. (2002). The culture of Mexican migration: a theoretical and empirical analysis. Social Forces, 80(3), 981-1004.

Le Roux, B. \& Rouanet, H. (2010). Multiple correspondence analysis. Thousand Oaks, Cal.: Sara Miller McCune, Sage Publications.

Leite, P., Angoa, M. A. \& Rodríguez, M. (2009). Emigración mexicana a Estados Unidos: balance de las últimas décadas. En Consejo Nacional de Población, La 
situación demográfica de México 2009 (pp. 103-123). México: Consejo Nacional de Población.

Lindstrom, D. \& Lauster, N. (2001). Local economic opportunity and the competing risks of internal and U.S. migration in Zacatecas, Mexico. International Migration Review, 35(4), 1232-1256.

Lindstrom, D. \& López-Ramírez, A. (2010). Pioneers and followers: migrant selectivity and the development of US migration streams in Latin America. The Annals of the American Academy of Political and Social Science, 630(1), 53-77.

Lowell, L. (2006). El cambiante perfil educativo y la selectividad de las inmigrantes mexicanos en Estados Unidos. México: Consejo Nacional de Población, Universidad de Guadalajara, Centro de Investigaciones y Estudios Superiores en Antropología Social, Casa Juan Pablos, El Colegio de México.

Lozano-Ascencio, F., Roberts, B., \& Bean, F. (1996). The interconnectedness of internal and international migration: the case of the United States and Mexico. Austin: University of Texas at Austin.

Martínez, F. (2002). Nueva visita al país de la desigualdad. La distribución de la escolaridad en México, 1970-2000. Revista Mexicana de Investigación Educativa, 7(16), 415-443.

Masferrer, C. \& Roberts, B. (2012). Going back home? Changing demography and geography of Mexican return migration. Population Research and Policy Review, 31(4), 465-496.

Massey, D. (1990). Social structure, household strategies, and the cumulative causation of migration. Population Index, 56(1), 3-26.

Massey, D., Arango, J., Graeme, H., Kouaouci, A., Pellegrino, A., \& Taylor, J. E. (2000). Teorías sobre la migración internacional: una reseña y una evaluación. Trabajo, 2(3), 5-50.

McKenzie, D. \& Rapoport, H. (2007). Network effects and the dynamics of migration and inequality: theory and evidence from Mexico. Journal of Development Economics, 84(1), 1-24. Recuperado de http://www.sciencedirec.com/science/ article/pii/S0304387806001891

Mincer, J. (1978). Family migration decisions. Journal of Political Economy, 86(5), 749773.

Minnesota Population Center (2017). Integrated public use microdata series, international. Minneapolis: University of Minnesota. Recuperado de https://international.ipums.org/international/index.shtml

Nevins, J. (2010). Operation Gatekeeper and beyond: the war on "illegals" and the remaking of the U.S.-Mexico boundary (2nd ed.). Routledge. 
Partida, V. (2000). Migración en la vejez y reunificación familiar. En Consejo Nacional de Población, La situación demográfica de México 2000 (pp. 117-130). México: Consejo Nacional de Población.

Partida, V. (2001). La migración interna. México: Consejo Nacional de Población, Fondo de Cultura Económica.

Partida, V. (2010). Migración interna. En García, B. \& Ordorica, M. (eds.), Los grandes problemas de México (vol. I, Población, pp. 325-361). México: El Colegio de México.

Partida, V., \& Martínez, M. A. (2006). Migración interna. México: Consejo Nacional de Población.

Passel, J., Cohn, D. \& Gonzalez-Barrera, A. (2012). Net migration from Mexico falls to zero-and perhaps less. Washington: Pew Hispanic Center. Recuperado de http://www.pewhispanic.org/2012/04/23/net-migration-from-mexico-falls-tozero-and-perhaps-less/

Pew Hispanic Center (2011). The Mexican-American boom: births overtake immigration. Washington: Pew Hispanic Center. Recuperado de http://www.pewhispanic.org/2011/07/14/the-mexican-american-boombrbirths-overtake-immigration/

Ramírez, A. (2008). Migración, remesas y arreglos residenciales de los adultos mayores en México. Estudios Demográficos y Urbanos, 23(3), 513-541.

Rodríguez, J. (2004). Migración interna en América Latina y el Caribe: estudio regional del período 1980-2000. Santiago de Chile: Comisión Económica para América Latina y el Caribe.

Rodríguez, J. \& Busso, G. (2009). Migración interna y desarrollo en América Latina entre 1980 y 2005: un estudio comparativo con perspectiva regional basado en siete países. Santiago de Chile: Comisión Económica para América Latina y el Caribe.

Rogers, A. \& Castro, L. (1982). Patrones modelo de migración. Demografía y Economía, 16(3), 267-327.

Romo, R. \& Téllez, Y. (2013). Tendencias de la migración interna en México en el periodo reciente. En Consejo Nacional de Población, La situación demográfica de México 2013 (pp. 88-106). México: Consejo Nacional de Población.

Ruggles, S., Genadek, K., Goeken, R., Grover, J., \& Sobek, M. (2015). Integrated Public Use Micradata Series: Version 6.0. Minneapolis: University of Minnesota.

Secretaría de Educación Pública (s.f.). Tablas de correspondencia: primaria, secundaria y bachillerato. Recuperado de http://www.ree.sep.gob.mx/work/ models/sincree/Resource/archivo_pdf/tablas_de_correspondencias.pdf

Skeldon, R. (1977). The evolution of migration patterns during urbanization in Peru. Geographical Review, 67(4), 394-411. 
Sobrino, J. (2010). Migración interna en México durante el siglo XX. México: Consejo Nacional de Población.

Szasz, I. (1994). Migración y relaciones sociales de género: aportes desde la perspectiva antropológica. Estudios Demográficos y Urbanos, 9(1), 129-150.

Szasz, I. (1999). Perspectiva de género y migración femenina en México. En García, B. (ed.), Mujer, género y población en México (pp. 167-210). México: El Colegio de México, Sociedad Mexicana de Demografía.

Todaro, M. P. (1969). A model of labor migration and urban unemployment in less developed countries. The American Economic Review, 59(1), 138-148.

Todaro, M. P. (1976). Internal migration in developing countries: a review of theory, evidence, methodology and research priorities. Geneva: International Labour Office.

Tuirán, R. \& Ávila, J. L. (2010). La migración México-Estados Unidos, 1940-2010. En F. Alba, M. A., Castillo, \& Verduzco, G. (eds.), Los grandes problemas de México (vol. III, Migraciones internacionales, pp. 93-134). Mexico: El Colegio de México.

Verduzco, G. (2010). Las regiones de México ante las migraciones a Estados Unidos. México: ElColegio de México.

Villarreal, A. (2014). Explaining the decline in Mexico-US migration: the effect of the Great Recesion. Demography, 51(6), 2203-2228.

White, M. J. \& Lindstrom, D. (2005). Internal migration. En Poston, D. \& Micklin, M. (eds.), Handbook of population (pp. 311-346). Springer Science+Business Media.

Zelinsky, W. (1971). The hypothesis of the mobility transition. Geographical Review, $61(2)$.

Zenteno, R. (2012). Saldo migratorio nulo: el retorno y la política anti-inmigrante. Coyuntura Demográfica, 2, 17-21. 